\title{
The glioma-amplified sequence 41 gene (GAS41) is a direct Myb target gene
}

\author{
Daniel Braas, Holger Gundelach and Karl-Heinz Klempnauer
}

Institut für Biochemie, Westfälische Wilhelms-Universität Münster, Wilhelm-Klemm Str.2, D-48149 Münster, Germany

Received as resubmission July 4, 2004; Accepted August 17, 2004

\begin{abstract}
The retroviral oncogene v-myb encodes a transcription factor ( $v-M y b)$ which transforms myelomonocytic cells in vivo and in vitro. It is thought that $\mathrm{v}$-Myb exerts its biological effects by deregulating the expression of specific target genes, most of which are still unknown. The chicken glioma-amplified sequence 41 gene (GAS41) is located immediately downstream of the lysozyme gene, a known Myb-regulated gene. The GAS41 promoter colocalizes with a CpG island which also functions as an origin of replication. Since the GAS41 promoter contains several potential Mybbinding sites (MBSs) we have investigated whether GAS41 is a v-Myb target gene. Our results show that the GAS41 gene is directly activated by a v-Myb/estrogen receptor fusion protein. Furthermore, our studies reveal that the GAS41 promoter is stimulated by $\mathrm{v}$-Myb in co-transfection experiments and that the DNA-binding activity of $\mathrm{v}-\mathrm{Myb}$ is crucial for transactivation of the promoter. Electrophoretic mobility-shift assays (EMSA) indicate that several Myb-binding sites, residing $\sim 250 \mathrm{bp}$ upstream of the transcriptional start site, are bound by Myb in vitro. Furthermore, chromatin immunoprecipitation assays demonstrate that $\mathrm{v}-\mathrm{Myb}$ is bound to the GAS41 promoter in vivo. Taken together these findings identify the GAS41 gene as a novel v-Myb target gene. We have also analysed the GAS41 replication origin in myelomonocytic cells and have failed to observe significant differences in origin activity in cells expressing or not expressing v-Myb.
\end{abstract}

\section{INTRODUCTION}

The glioma-amplified sequence 41 gene (GAS41) was originally isolated from a glioma cell line (1) and was shown to be frequently amplified in glial tumours (2) which account for $40 \%$ of the central nervous system tumours $(3,4)$. The GAS41 protein is highly conserved among humans (U61384), mice (AA529582), chickens (AJ396415), Drosophila melanogaster (AAF52462) and Caenorhabditis elegans (CAB1234) (5). It lies immediately downstream of the well-studied lysozyme gene which is known to be flanked by two matrix attachment regions (MARs) (6). The location of GAS41 with respect to the lysozyme gene is conserved among human (12q13-q15), mouse (chromosome 10D2) and chicken (accession no. AF410481). The GAS41 protein is related to the human AF-9 and ENL transcription factors (2) and contains a potential $\alpha$-helical acidic activation domain, as is found in many eukaryotic transcription factors (7). GAS41 was recently found to be an interaction partner of the human MLL-AF10 fusion protein which is detected in $\sim 5-10 \%$ of human acute leukaemias (8) thus linking GAS41 overexpression to human malignant transformation. In addition, Debernardi et al. (8) have shown that GAS41 interacts with INI1 (Integrase Interactor 1) which is the human homologue of the yeast SNF5 protein. SNF5 is a component of the SWI/SNF complex which in turn is known for its ATP-dependent chromatin remodelling activity (9). The GAS41 protein is located mainly in the interphase nucleus, but not in the nucleolus, and is uniformly distributed in the cell during mitosis (10). Harborth et al. (10) have also reported that GAS41 interacts with NuMA (nuclear mitotic apparatus protein) which is a component of the nuclear matrix in interphase cells. The GAS41 gene is ubiquitously expressed in humans and chickens. It has been shown that GAS41 is essential for cell viability, as a homozygous GAS41deficient cell line could not be obtained by homologous recombination. However, both copies of the gene could be disrupted in the presence of a tetracycline-regulated GAS41 cDNA. When tetracycline is withdrawn from these cells, total RNA synthesis is drastically decreased leading to cell death (11).

The retroviral oncogene $\mathrm{v}-m y b$ encodes a transcription factor that transforms myelomonocytic cells and causes leukaemia in chickens [reviewed in (12)]. The protooncogene c- $m y b$, from which $\mathrm{v}-m y b$ is derived, is highly expressed in most haematopoietic progenitor cells and is essential for the development of the haematopoietic system. It has been shown that mice lacking a functional c-myb gene die during embryonic development because of multiple defects of the haematopoietic system (13). The proteins encoded by v- $m y b$ and c- $m y b$ bind to the sequence motif PyAA $\mathrm{C} / \mathrm{T} \mathrm{G}(14)$ and activate promoters containing such sites (15-18). It is generally believed that cell transformation by $\mathrm{v}-m y b$ is caused by the activation of specific target genes. Until now, a number of genes have been identified as bona fide Myb target genes, including mim-1 (16), the lysozyme gene (19), bcl-2 (20,21), tom-1 (22) and GBX2 (23) among others. Some of these genes have been studied in detail; however, it has not yet been established whether any of the known Myb target genes play a crucial role in cell transformation by v-Myb.

*To whom correspondence should be addressed. Tel: +49 251 8333203; Fax: +49 251 8333206; Email: klempna@uni-muenster.de 


\section{MATERIALS AND METHODS}

\section{Cell culture}

The chicken cell lines BM2 (AMV-transformed myeloblasts) and HD11 (MC29-transformed macrophages) have been described previously (24,25). 10.4 is a derivative of the HD11 cell line expressing an E26 v-Myb/ER fusion protein (26). To investigate the direct stimulation of the cGAS41 gene 10.4 cells were treated with $50 \mu \mathrm{g} / \mathrm{ml}$ cycloheximide for $15 \mathrm{~min}$ and then incubated in the presence or absence of $2 \mu \mathrm{M} \beta$-estradiol for a further $5 \mathrm{~h}$.

\section{Northern blotting}

Preparation of polyadenylated RNA and northern blotting were performed as described in (24). As an internal control for mRNA quantities, a specific probe for the ribosomal S17 gene was used.

\section{Reporter genes and transfections}

The luciferase reporter genes were constructed by cloning a 1.3 or a $0.4 \mathrm{~kb}$ GAS41-promoter fragment into the luciferase vector pGL3-Basic (Promega). Co-transfection experiments with different Myb-expressing vectors were performed using either an E26 v-Myb (pCDE26 v-myb) or an AMV Myb expression vector (pCDAMV v-myb). As a control an empty expression vector (pcDNA3) was co-transfected. Alternatively, an expression vector for an AMV v-Myb mutant lacking the DNA binding domain (pVM 130) or the corresponding empty expression vector (pVM 111) was used. All vectors have been described previously $(15,27)$. The $\beta$-galactosidase reporter gene $\mathrm{pCMV} \beta$ was obtained from Clontech. Transfection experiments were performed by calcium phosphate coprecipitation as described in (24).

\section{Electrophoretic mobility-shift assay (EMSA)}

The following pairs of single-stranded oligonucleotides were annealedand usedforEMSAs:Myb1+2_sense, 5'-GCTACCCGCTTGGCAGTTTTAAACGCATCCCTCAAT- $3^{\prime}$;Myb1+2_anti, $5^{\prime}$-AATGAGGGATGCGTTTAAAACTGCCAAGCGGGTAG- ${ }^{\prime}$; Myb3 _sense, $5^{\prime}$-TCCCTCATTAAAACGACTTATACG-3' ${ }^{\prime}$;Myb3_anti, $\overline{5}^{\prime}$-GCGTATAGTCGTTTTAATGAGGGA-3' ${ }^{\prime}$;Myb4_sense, $5^{\prime}$-ACTATACGCAAACGCCTTCCCGT-3'; and Myb4_anti, 5'-GACGGGAAGGCGTTTGCGTAT AGT-3'. After annealing, oligonucleotides were radiolabelled by filling-in the ends using $\left[\alpha-{ }^{32} \mathrm{P}\right] \mathrm{dCTP}$. Preparation of bacterial full-length $\mathrm{v}-\mathrm{Myb}$ protein and binding experiments were performed as described previously (28).

\section{Chromatin immunoprecipitation (ChIP)}

Approximately $10^{8} \mathrm{BM} 2$ or HD1 1 cells were incubated in 1/10 crosslinking solution containing $0.1 \mathrm{M} \mathrm{NaCl}, 1 \mathrm{mM}$ EDTA, $0.5 \mathrm{mM}$ EGTA, $50 \mathrm{mM}$ Tris- $\mathrm{HCl}, \mathrm{pH} 8.0$, and $11 \%$ formaldehyde for $1 \mathrm{~h}$ and quenched for $5 \mathrm{~min}$ in $125 \mathrm{mM}$ glycine. After washing in ice-cold phosphate-buffered saline, the cells were treated for $20 \mathrm{~min}$ each with washing solutions A $(0.25 \%$ Triton X-100, $10 \mathrm{mM}$ Tris- $\mathrm{HCl}, \mathrm{pH} 8.0,10 \mathrm{mM}$ EDTA, $0.5 \mathrm{mM}$ EGTA) and B (200 mM NaCl, $10 \mathrm{mM}$ Tris- $\mathrm{HCl}$, pH 8.0, 1 mM EDTA, 0.5 mM EGTA). Nuclei were sonicated on ice (4 times for $20 \mathrm{~s}$ in 2 min intervals) in egg lysis buffer (ELB) (120 mM NaCl, 50 mM Tris-HCl, pH 7.5, 20 mM NaF,
$1 \mathrm{mM}$ EDTA, $6 \mathrm{mM}$ EGTA, $15 \mathrm{mM}$ sodiumpyrophosphate, $1 \mathrm{mM}$ phenylmethylsulfonyl fluoride and $0.1 \%$ Nonidet P-40). DNA-protein complexes were incubated with two different Myb-specific antibodies, normal rabbit serum or no antibody. After precipitating with protein-A-Sepharose, the samples were washed several times in ELB buffer. Following elution with $0.5 \%$ SDS the DNA was recovered by reverse-crosslinking for $6 \mathrm{~h}$ at 37 and $65^{\circ} \mathrm{C}$, respectively, in a buffer containing $0.5 \%$ SDS; $10 \mathrm{mM}$ DTT and $100 \mu \mathrm{g}$ proteinase $\mathrm{K}$. The immunoprecipitated DNA was then purified by phenolchloroform extraction and ethanol precipitation. PCR amplification was performed with primers specific for the chicken GAS41 promoter region, forward 5'-GTGTTTCCCGCTTCCTTTCTTAA-3' and reverse 5'-GCGTTCATGCCGTTTCCAT-3'. Alternatively, Lysozyme intron-2-specific primers, forward 5'-GGTAGTAAAAGCTTGACCCTTGCA-3' and reverse 5'-GTTCACCTCTCCTCCCCTTCA-3' were used. PCR products were resolved on a $10 \%$ polyacrylamide gel and stained with ethidium bromide.

\section{Nascent strand abundance assay}

Analysis of replication origin activity was performed according to Giacca et al. (29). Total genomic DNA was isolated from $\sim 10^{8}$ exponentially growing HD11 or BM2 cells with Nucleobond CB kit (Macherey\&Nagel) following the manufacturer's instructions. DNA was resuspended in TNE buffer (10 mM Tris-HCl, pH 8.0, $100 \mathrm{mM} \mathrm{NaCl}, 1 \mathrm{mM}$ EDTA) was heat-denatured for $8 \mathrm{~min}$ at $95^{\circ} \mathrm{C}$ followed by rapid cooling on ice. Denatured DNA was layered on a linear neutral sucrose gradient (5-30\% in TNE) and size fractionated by centrifugation in a Beckman SW28 rotor at 26000 r.p.m. for $20 \mathrm{~h}$ at $20^{\circ} \mathrm{C}$. Nascent strand DNA fractions with an average DNA size of $1-1.5 \mathrm{~kb}$ were precipitated with ethanol and resuspended in TE buffer (10 mM Tris-HCl, pH 8.0, $1 \mathrm{mM}$ EDTA). The purified nascent DNA strands were analysed by quantitative real-time PCR using the following primer pairs: Lys_-8.1 kb_for 5'-AAGCTTCAGCAGGTCATTGT CTT-3'; Lys_-8.1 kb_rev 5'-GCTTCGACATCAGTTCCACTCT-3'; Lys-In2(+1.9 kb)_for 5'-GGTAGTAAAAGCTTGACCCTTGCA-3'; Lys-In2(+1.9 kb)_rev 5'-GTTCACCTCTC CTCCCCTTCA-3'; GAS-prom(+3.3 kb)_for 5'-GTGTTTCCCGCTTCCTTTCTTAA-3'; GAS-prom(+3.3 kb)_rev 5'-GCGTTCATGCCGTTTCCAT-3'; Lys_+4.7 kb_for $5^{\prime}$-GGAGCTGACTGAGCTCCCTTTC-3'; Lys_+4.7 kb_rev 5'-AGCCAAATGCAGCCAAAGC-3'; Lys_+8.8 kb_for $5^{\prime}$-ATCGTGTGATTTTCGGATGGAA-3'; Lys_+8.8 kb_rev 5'-ATCTCG GCTTTCAATAGGCTTTTC-3'.

\section{Real-time PCR quantification}

Q-PCR was carried out on a GeneAmp 5700 SDS (Applied Biosystems) with the qPCR Core kit for SYBR I (Eurogentec) following the manufacturer's instructions. Primers were chosen with PrimerExpress 2.0 Software (Applied Biosystems). A 5-fold serial dilution of sheared genomic DNA with a known concentration was used to create a standard curve. Genomic equivalents ( 1 genomic equivalent $\left.=1.25 \times 10^{-12} \mathrm{~g}\right)$ of the samples were extrapolated and relative abundance was calculated. The specificity of the PCR products was checked by melting curve analysis and agarose gel electrophoresis (data not shown). 


\section{RESULTS}

Expression of GAS41 mRNA is induced by v-Myb

Recently, the GAS41 gene has attracted our attention as a potential Myb-regulated gene. It was shown that the GAS4I gene resides very close to a known Myb target gene, the chicken lysozyme gene (6). The lysozyme gene is embedded in a $24 \mathrm{~kb}$ domain of general DNaseI sensitivity that is flanked by two boundary elements that coincide with MARs [(30); for review see (31)]. It has been shown that a set of DNaseIhypersensitive sites (DHSs) are necessary for correct spatial and temporal expression of the gene (32). The GAS41 gene is situated immediately downstream of the chicken lysozyme gene (Figure 1) and, thus, lies within its transcriptional domain

A
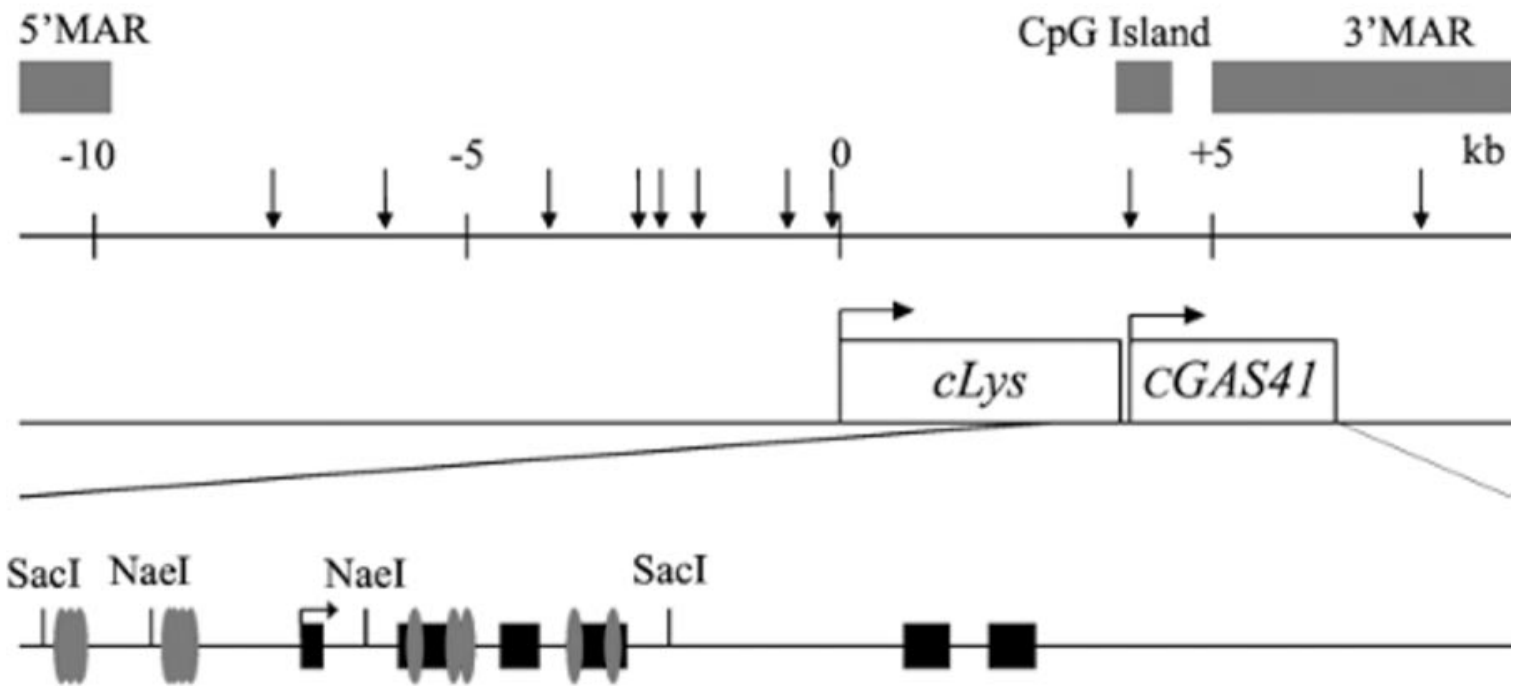

B

GTGTTTCCCGCTTCCTTTCTTAAGCCCTGCT $\frac{\text { SacI }}{\text { AGCTCAGACAT }}$ A ACA GCGAGCG T GAACTGCGCGA A GA A A T C G T CA G C GAT G GA AACGGCAT GAACGC GT G G T A G T G GCGGGGGGT T C C A GGA A GCCCCCAGCGCGGA CG GCAGCGCCGTCACTCACCGCTCCGTCT C C C T C C G C C CA G G G T C G C C T G G C G C A A C C G C T G CAAG G C A C NaeI

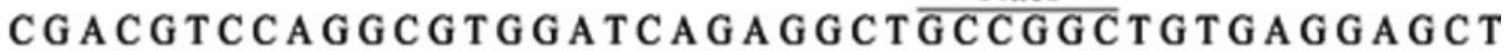
GCCGCG C C G G C C C G C C G C T G CACA GCCGG C G C T T T G C GA G C G C G A C G C T A C C C G C T T G G CAGTTT T A AACG C A T C C C T C A T T A A AACGA C T A T A C G C AAACG C C T T C C C G T C G G T C C G C G T C T C T T T C C GCCGCCA G G GCGACACT C C G G G A G G G C G G A A G G G G C C G G G C G G G A G C C C G C G G C C A A C C G T C G C C C C T GA CG G C A C C G C C C C G C C C CG T GA C G C T T G G G C C C GGGGCCGTGGGGCT GA GC GCT GCG GCGGGGCCGGG C CGGGCCGGGGCGGGA GCT G A G C G C GGCGCGGCTGCGGGCGGCGCCCCCTCCGGTGCAATATGTTCAAG A GAAT G GCTGAGTTCGGGCCTGACTCCGGGGGCAGGGTGAAGT G C G G C G C G G G G G A G G A C G G GG C G G G C G C G G G C C G C C G G C NaeI

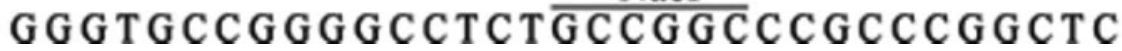

Figure 1. Transcriptional domain of the lysozyme ( $c L y s)$ and $c G A S 41$ gene. (A) Grey boxes mark the boundaries of the general DNaseI-sensitive region and coincide with MARs. The location of a CpG-island which contains the GAS41 promoter is also indicated as a grey box. DHSs within this domain are shown as vertical arrows. The orientation of the lysozyme and the GAS41 genes and their transcriptional start sites are visible as open boxes and arrows. At the bottom the region of the GAS4I gene is expanded. Potential MBSs are displayed as grey ovals and exons as dark boxes. For better orientation, SacI and NaeI restriction sites are shown. (B) Nucleotide sequence of the promoter region of the GAS41 gene. Annealing sites for primers used in ChIP experiments are shown underlined, potential MBSs are marked with boxes. The transcriptional start site is indicated by an arrow. For better orientation one SacI and both NaeI restriction sites are shown. 
(6). The promoter of the GAS41 gene coincides with a $\mathrm{CpG}$ island. In addition, Phi-van and coworkers $(33,34)$ showed that an origin of bidirectional replication (OBR) is located within the $\mathrm{CpG}$ island of the GAS41 promoter (Figure 1A). Interestingly, the cell-type-specific expression patterns of the lysozyme and GAS41 genes are very different. While the expression of the lysozyme gene is restricted to certain cell types, such as myelomonocytic cells, GAS41 appears to be ubiquitously expressed. Since the chicken lysozyme gene is a direct Myb target gene and since the GAS41 promoter region contains several potential Myb binding sites (Figure 1B), we were interested to know whether GAS41 is also an Myb target gene.

To determine whether GAS4I expression is regulated by Myb we performed northern blot analyses with polyadenylated RNA of 10.4 cells. 10.4 is a subclone of the chicken macrophage cell line HD11 stably expressing a v-Myb/estrogen receptor fusion protein (26). Upon $\beta$-estradiol treatment the $\mathrm{v}$-Myb/ER fusion protein is activated and upregulates the expression of a number of Myb target genes $(22,26,35,36)$. 10.4 cells were cultivated for $24 \mathrm{~h}$ in the presence or absence of $2 \mu \mathrm{M} \beta$-estradiol. Polyadenylated RNA from these cells was then isolated and analysed by northern blotting with probes specific for GAS41, the lysozyme gene and, as an internal control, the ribosomal $S 17$ gene (Figure 2A). As shown in Figure 2A, GAS4I mRNA level was higher in estrogen-treated 10.4 cells compared to untreated cells, suggesting that chicken GAS41 is indeed an Myb target gene. The effect of v-Myb on the expression of GAS41 was lower than its effect on the expression of the lysozyme gene, indicating that both genes are regulated independently by Myb.

\section{v-Myb directly increases GAS41 mRNA expression}

We next wished to know if GAS4I is directly activated by $\mathrm{v}$-Myb/ER. It had been shown that treatment of 10.4 cells with $\beta$-estradiol does not alter v-Myb/ER expression but solely activates the fusion protein independently of de novo protein synthesis $(22,26)$. The v-Myb/ER system, therefore, allows to investigate if a particular gene is directly induced by $\mathrm{v}-\mathrm{Myb}$ by analysing the effect of $\beta$-estradiol on this gene in the presence or absence of a protein synthesis inhibitor, such as cycloheximide $(22,26)$. To determine if the stimulation of GAS41 expression by $\mathrm{v}-\mathrm{Myb}$ is direct, 10.4 cells were cultivated in the presence or absence of $50 \mu \mathrm{g} / \mathrm{ml}$ cycloheximide for $15 \mathrm{~min}$, prior to addition of $\beta$-estradiol, and further incubated for $5 \mathrm{~h}$. We treated the cells for only $5 \mathrm{~h}$ with $\beta$-estradiol (as opposed to $24 \mathrm{~h}$ in the experiment shown in Figure 2A) to minimize the toxic effects of cycloheximide. Polyadenylated RNA was prepared from these cells and analysed by northern blotting. A representative experiment is illustrated in Figure 2B. As shown in this figure activation of GAS4I by v-Myb was observed in the absence as well as in the presence of cycloheximide. Since the induction of Myb target gene expression by $\mathrm{v}-\mathrm{Myb} / \mathrm{ER}$ increases with time after addition of $\beta$-estradiol $(26,36)$, the overall induction by $\mathrm{v}-\mathrm{Myb} / \mathrm{ER}$ is lower in Figure $2 \mathrm{~B}(5 \mathrm{~h}$ treatment with $\beta$-estradiol) than in Figure 2A (24 $\mathrm{h}$ treatment). To rule out that this effect is restricted to GAS41, we also analysed the expression of lyzozyme (Figure 2B) which is known to be highly Myb-inducible (Figure 2A). Under these conditions lysozyme expression is drastically lowered. From the data shown in Figure 2B we concluded that v-Myb directly induces GAS4I expression.
A

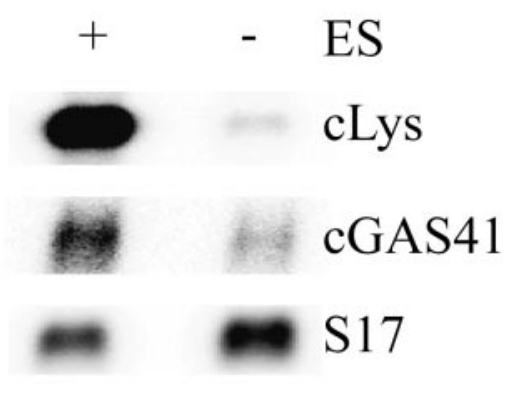

B
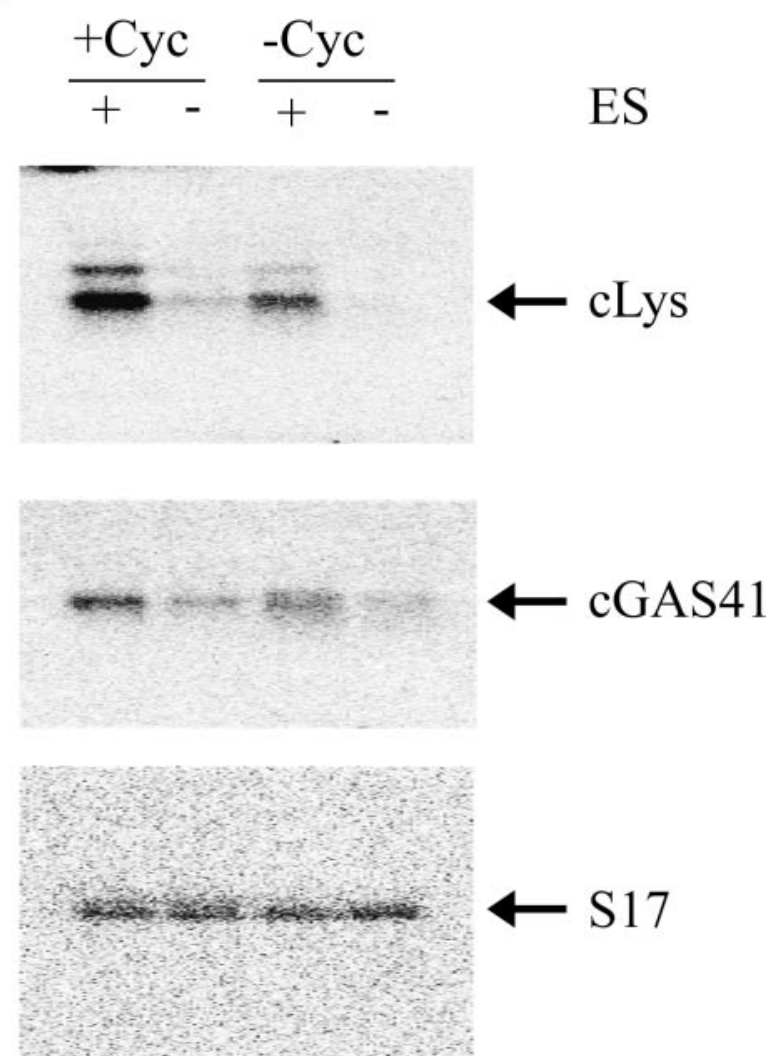

Figure 2. Induction of GAS41 expression by a v-Myb/ER fusion protein. (A) Polyadenylated RNA from 10.4 cells grown for $24 \mathrm{~h}$ in the presence $(+\mathrm{ES})$ or absence $(-\mathrm{ES})$ of $2 \mu \mathrm{M} \beta$-estradiol was analysed by a northern blot experiment using a GAS41-specific probe (middle). For comparison, induction of lysozyme (cLys) expression is shown at the top. Expression of the chicken $S 17$ gene was analysed as a control (bottom). (B) Stimulation of GAS41 expression in the presence of cycloheximide. 10.4 cells were grown in the presence $(+\mathrm{Cyc})$ or absence $(-\mathrm{Cyc})$ of $50 \mu \mathrm{g} / \mathrm{ml}$ cycloheximide either with $(+\mathrm{ES})$ or without ( - ES) $2 \mu \mathrm{M} \beta$-estradiol. Cycloheximide was added to the cultures $15 \mathrm{~min}$ prior to hormone treatment. Cells were cultivated for $5 \mathrm{~h}$ and polyadenylated RNA was analysed by a northern blot experiment using a lysozyme- (top) or a GAS41specific probe (middle). A chicken $S 17$ probe was used as control (bottom).

\section{The GAS41 promoter is stimulated by binding of $\mathrm{v}-\mathrm{Myb}$}

To provide further evidence for the idea that GAS4I is a direct Myb target gene, we performed transient transactivation studies with two different GAS4l promoter constructs. 
A schematic illustration of these reporter genes is shown in Figure 3. Potential $M y b$-binding sites are indicated as grey ovals. 10.4 cells expressing the $\mathrm{v}-\mathrm{Myb} / \mathrm{ER}$ fusion protein were transfected with the reporter genes and cultivated for $24 \mathrm{~h}$ in the presence or absence of $\beta$-estradiol before reporter gene activity was determined (Figure 3A). In case of both constructs, the luciferase expression levels were Myb inducible, supporting the idea that the GAS41 promoter can be stimulated by Myb. In addition, we transfected HD11 cells with these reporter genes and expression vectors encoding the
A
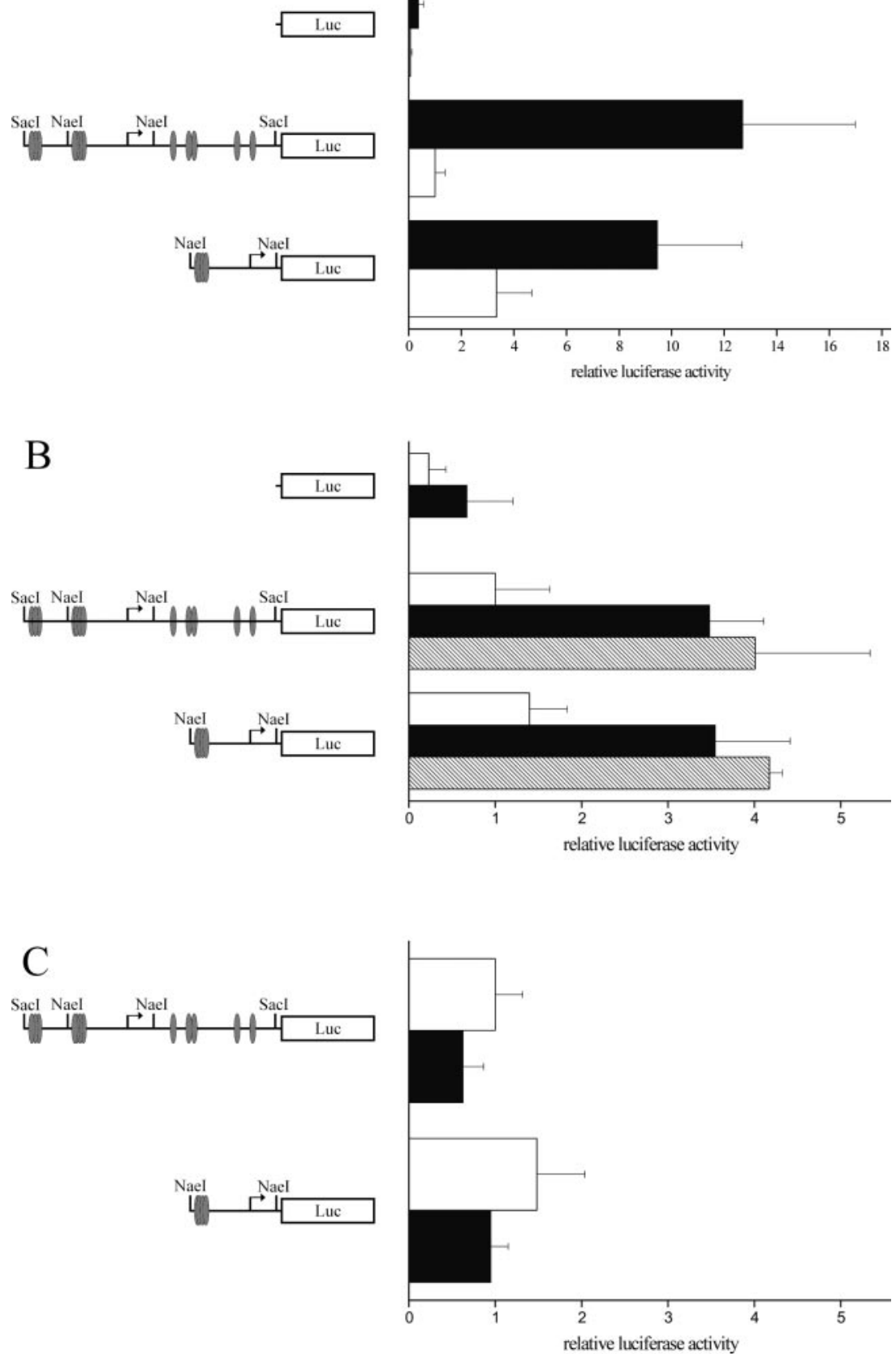

Figure 3. Activation of GAS41 reporter genes by v-Myb. GAS41 promoter reporter gene constructs used in transactivation studies are shown schematically at the left of each panel. The SacI and NaeI restriction sites that were used for cloning are marked. Potential Myb-binding sites are indicated as grey ovals. (A) Transient transfection experiments of the reporter gene constructs in 10.4 cells. Cells were transfected with $5 \mu \mathrm{g}$ of the reporter gene and $1 \mu \mathrm{g}$ of the $\beta$-galactosidase reference plasmid pCMV $\beta$ as described in (24). Cells were cultivated in the presence (black bars) or absence (white bars) of $2 \mu \mathrm{M} \beta$-estradiol. $24 \mathrm{~h}$ after transfection the cells were analysed for luciferase and $\beta$-galactosidase activity. The columns show the average relative luciferase activity of the reporter gene. Thin lines show the standard deviations. (B) HD1 1 cells were transfected as described in (A). In addition, $1 \mu \mathrm{g}$ of either AMV Myb or E26 v-Myb expressing vector, pCDAMVv-myb (hatched bars) and pCDE26v-myb (black bars), or of empty expression vector pCDNA3 (white bars) were co-transfected and analysed as described in (A). (C) To emphasize that DNA binding of v-Myb is important for transactivation $1 \mu \mathrm{g}$ of an expression vector for a v-Myb mutant lacking the DNA binding domain (pVM 130, black bars) or $1 \mu \mathrm{g}$ of the corresponding empty expression vector (pVM 111, white bars) were co-transfected into HD11 cells. Cells were transfected, harvested and analysed as described in (A). 
$\mathrm{V}-\mathrm{Myb}$ proteins of AMV and E26. Since the lysozyme gene is activated only by the E26 version of $\mathrm{v}-\mathrm{Myb}$ but not by that of AMV (19) we wanted to see if AMV and E26 Myb also differ with respect to GAS41. As shown in Figure 3B, both v-Myb variants activate the GAS41 constructs nearly to the same extent, although the induction by $\mathrm{v}-\mathrm{Myb}$ was somewhat lower in case of the HD11 cells compared to 10.4 cells. To further show that the DNA-binding activity of $\mathrm{v}-\mathrm{Myb}$ is crucial for activation of the GAS41 promoter, we used an expression vector for a v-Myb mutant that lacks the DNA binding domain (pVM130) (Figure 3C). In this case transactivation of the reporter gene constructs was not observed indicating that Myb binding is required for the activiation of the GAS4I promoter. Taken together, the experiments illustrated in Figure 3 support the idea that the GAS4I promoter is directly activated by Myb.

\section{In vitro binding of $\mathrm{v}-\mathrm{Myb}$ to the $G A S 41$ promoter}

To show that v-Myb is able to bind to the potential Mybbinding sites located nearest to the GAS41 transcription start site we performed EMSAs. Figure 4 depicts the pGL3GAS-0.4NaeI construct that was used for reporter gene assays and the four potential Myb-binding sites therein. Oligonucleotides used in the EMSA experiments are underlined. To show that Myb binds to these sites, in vitro recombinant protein was expressed in bacteria and used for binding assays as described in (28). Several major DNA-protein complexes can be
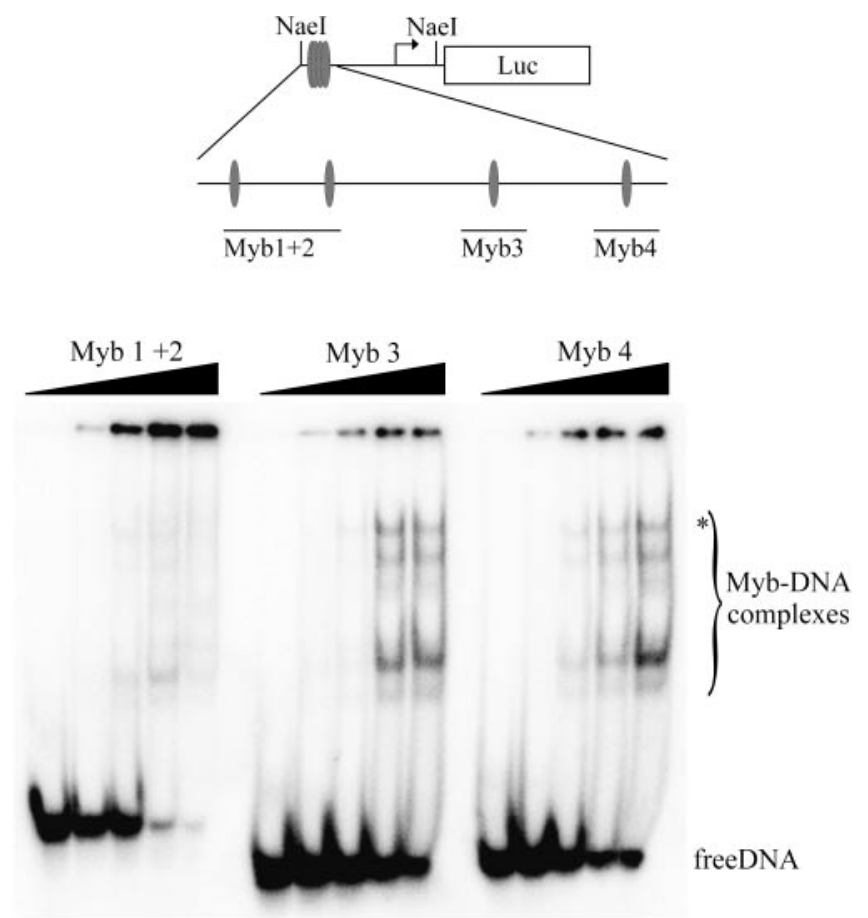

Figure 4. EMSA of the GAS41 promoter. The pGL3-GAS-0.4NaeI reporter gene construct and positions of Myb binding sites 1 to 4 are depicted (upper panel). The oligonucleotides used for the binding assays are drawn as lines below. Oligonucleotides were radioactively labelled and incubated with increasing amounts $(0-11 \mu \mathrm{l})$ of bacterially expressed v-Myb as described in (28). Due to partial proteolysis of the bacterial $\mathrm{v}$-Myb protein several Myb-DNA complexes are visible. The complex formed by full-length vMyb is marked by an asterisk. The intense bands at the bottom are unbound oligonucleotides. distinguished in Figure 4. These complexes are due to partial proteolysis of the $\mathrm{v}-\mathrm{Myb}$ protein preparation used in this array. The slowest migrating complex is formed by full-length $\mathrm{v}-\mathrm{Myb}$. We conclude from this experiment that $\mathrm{v}-\mathrm{Myb}$ binds in vitro to all of the four potential binding sites suggesting that they play a role in Myb induction of the GAS41 promoter.

\section{v-Myb is bound to the GAS41 promoter in vivo}

To demonstrate that v-Myb is bound to the GAS41 promoter in vivo we performed ChIP experiments using the v-Mybtransformed myeloblast line BM2 and the Myb non-expressing myeloid macrophage line HD11. The cells were formaldehyde-fixed, and the DNA-protein complexes obtained after sonication were immunoprecipitated with two different antibodies against Myb. As a control, parallel incubations with non-immune serum or without any antiserum were performed. After reverse-crosslinking of the immunoprecipitated DNA, the samples were analysed by PCR using primers specific for the GAS41 promoter region. The result of this experiment is illustrated in Figure 5A-D. The first two lanes of all panels show DNA samples that were precipitated with Myb-specific antibodies. Amplification of the GAS41 promoter region was only observed in samples derived from BM2 cells that express
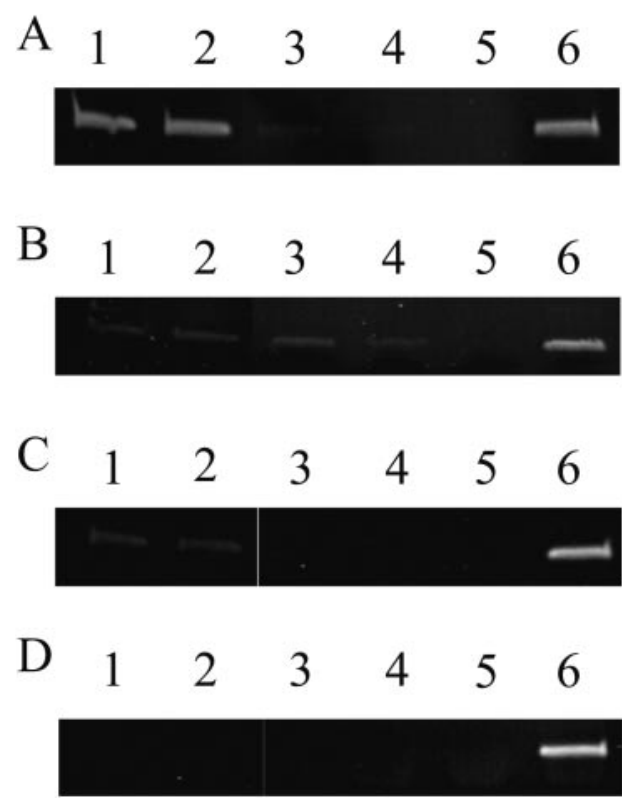

Figure 5. ChIP analysis of the GAS41 promoter. ChIP analysis was performed as described in Lefevre et al. (40). In brief, $\sim 10^{8} \mathrm{BM} 2$ (A and $\mathbf{C}$ ) or HD11 cells (B and D) were incubated in 1/10 crosslinking solution, 11\% formaldehyde, for $1 \mathrm{~h}$. After washing nuclei were sonicated on ice (4 times for $20 \mathrm{sec}$ in $2 \mathrm{~min}$ intervals) in ELB. DNA-protein complexes were incubated with two different Myb-specific antibodies (lanes 1 and 2), normal rabbit serum (lane 3) or water (lane 4). Precipitates were washed in ELB buffer and then eluted. Reverse crosslinking was performed for $6 \mathrm{~h}$ at 37 and $65^{\circ} \mathrm{C}$, respectively, in a buffer containing proteinase $\mathrm{K}$. The immunoprecipitated DNA was then purified by phenol-chloroform extraction and ethanol precipitation. PCR amplification of immunoprecipitated DNA was performed with the indicated samples (lanes 14), with water as no template control (lane 5) and with the sonicated and reversecrosslinked input DNA (lane 6), using primers specific for the chicken GAS4I promoter region (A and B) and for the chicken lysozyme intron 2 (C and D). PCR products were resolved on a $10 \%$ polyacrylamide gel and stained with ethidium bromide. 


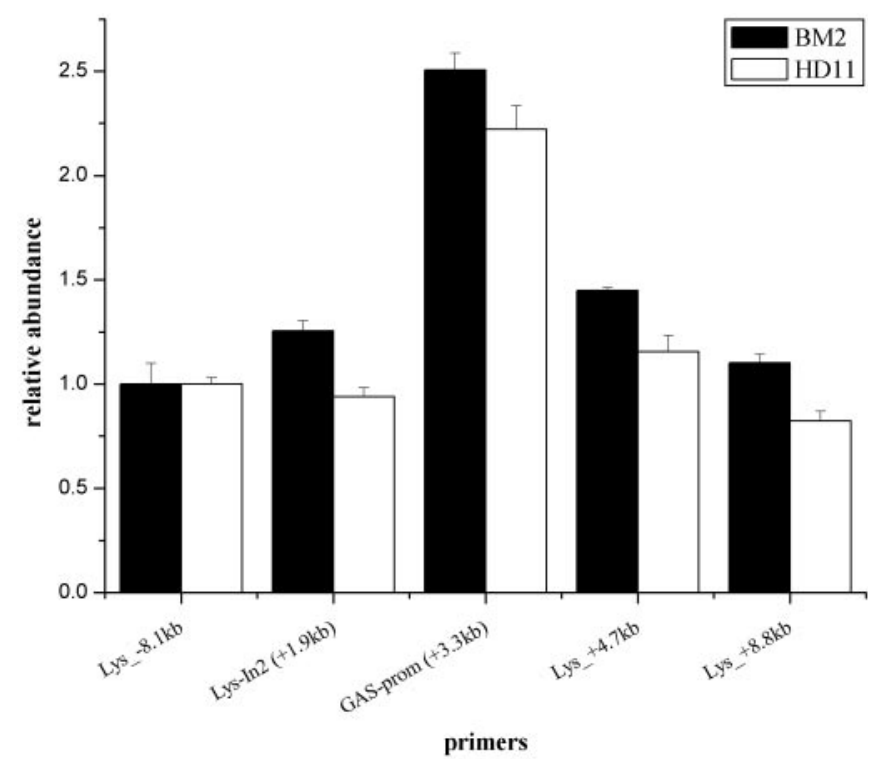

Figure 6. Nascent strand abundance assay of the GAS41 origin. A modified nascent strand abundance assay was used to map GAS41 origin activity within an $18 \mathrm{~kb}$ region (accession no. AF410481). For the quantification, real-time PCR was performed. Primer pairs used for PCR are designated corresponding to their position relative to the transcription start of the lysozyme gene. Columns show the average abundance of specific sequences in nascent strand preparations of BM2 and HD11 cells relative to the Lys_-8.1 kb primers. Error bars mark standard deviations.

v-Myb (Figure 5A). Samples derived from HD11 cells that lack v-Myb expression did not yield a PCR product (Figure 5B). Analysis of input samples (lanes 6) show that similar amounts of DNA were present before precipitation and negative controls (lanes 3-5) demonstrate the specificity of the assay. As an additional control we performed PCR reactions using primers that are specific for a part of the intron 2 of the chicken lysozyme gene. This region is $\sim 1.4 \mathrm{~kb}$ away from the region amplified by the GAS41 promoter-specific primers and lacks potential $M y b$-binding sites. Figure 5 shows that there was only a very weak signal in samples derived from BM2 cells (C) and none at all in those from HD11 cells (D) when Myb-specific antibodies were used. Therefore, the ChIP experiment clearly shows that v-Myb binds to the GAS41 promoter in vivo.

\section{Effect of v-Myb on GAS41 origin activity}

Since the GAS41 promoter region contains an origin of DNA replication $(33,34)$ we were interested to know whether the presence of $\mathrm{v}-\mathrm{Myb}$ effects the activity of the origin. We performed nascent strand abundance assay using BM2 and HD11 cells (Figure 6) to address this issue. These assays confirm the presence of a replication origin in this region; however, there was no significant difference between the two cell types.

\section{DISCUSSION}

The results described above provide strong evidence that the GAS41 gene is a direct Myb target gene in v-myb transformed myeloid cells. Amplification of the GAS41 gene has been implicated in the development of glial tumours (1) and recent analysis of its binding partners in cancer cells directly links
GAS41 overexpression to acute leukaemia in human (8). Its interaction with INI1 (Integrase Interactor 1) (8) which is a component of the human SWI/SNF complex suggests that GAS41 might play a role in either chromatin remodelling or in recruiting chromatin remodelling complexes (9). However, its physiological function is not yet fully understood since GAS41 is expressed in many cell types, including haematopoietic cells (6). Furthermore, knock-out of GAS4I leads to a global decrease of transcriptional activity and is incompatible with cell viability (11). The role of GAS41 in v-Myb-transformed cells is presently unknown. Further insight into its role will depend on further characterization of the biochemical function.

The observation by Chong et al. (6) that the GAS41 gene is situated immediately downstream of the lysozyme gene is quite surprising given that the cell-type-specific expression patterns of both genes are completely different. Despite their close proximity and the absence of any known boundary elements between them, both genes appear to be regulated independently. For example, the upstream region of the lysozyme gene contains several enhancers and silencers that direct the cell-type- and stage-specific expression of the lysozyme gene in myelomonocytic cells, apparently without affecting the expression of the GAS41 gene. The effect of Myb on the expression of both genes is also quite different, not only in magnitude but also with respect to the involvement of $\mathrm{C} / \mathrm{EBP}$ transcription factors. As shown before, the lysozyme gene is activated by Myb together with a member of the C/EBP transcription factor family $(24,37)$. In contrast, co-transfection experiments of the GAS41 promoter with C/EBP expression vectors have not shown any cooperativity between Myb and C/EBP (data not shown). Finally, it is of note that the GAS41 promoter region also acts as an origin of DNA replication $(33,34)$. The presence of a number of Myb binding sites in this region raises the question of whether Myb, in addition to affecting GAS4l's transcription, might also affect the activity of this region as a replication origin. In this respect it is interesting to note that Myb has already been linked to DNA replication in Drosophila melanogaster (38). However, our studies showed that there is no significant difference in origin usage between Myb-expressing BM2 and non-expressing HD11 macrophages (Figure 6). This finding is plausible in the context of the observations made by Danis et al. (39) since the GAS41 promoter lies within a CpG island. Therefore, this region is very likely to be easily accessible by DNA polymerase and might provide the origin function in almost all cell types. In summary, our work identifies the lysozymeGAS41 gene region as an interesting genomic locus containing two Myb target genes side-by-side. The further analysis of the molecular mechanisms involved in Myb-dependent regulation of both genes will probably provide interesting insight into how Myb activates the expression of cellular genes.

\section{ACKNOWLEDGEMENTS}

We thank Loc Phi-van for providing a chicken GAS41-specific probe and $\mathrm{C}$. Bonifer for a plasmid containing the lysozymeGAS41 genomic region. This work was funded by a grant from DFG (KL461/10-1). D.B. is supported by the Studienstiftung des deutschen Volkes and the Fonds der chemischen Industrie. 


\section{REFERENCES}

1. Fischer,U., Meltzer,P. and Meese,E. (1996) Twelve amplified and expressed genes localized in a single domain in glioma. Hum. Genet., 98, 625-628.

2. Fischer,U., Heckel,D., Michel,A., Janka,M., Hulsebos,T. and Meese,E. (1997) Cloning of a novel transcription factor-like gene amplified in human glioma including astrocytoma grade I. Hum. Mol. Genet., 6, 1817-1822.

3. Sehgal,A. (1998) Molecular changes during the genesis of human gliomas. Semin. Surg. Oncol., 14, 3-12.

4. Kleihues,P., Soylemezoglu,F., Schauble,B., Scheithauer,B.W. and Burger,P.C. (1995) Histopathology, classification, and grading of gliomas. Glia, 15, 211-221.

5. Munnia,A., Schutz,N., Romeike,B.F., Maldener,E., Glass,B., Maas,R., Nastainczyk,W., Feiden,W., Fischer,U. and Meese,E. (2001) Expression, cellular distribution and protein binding of the glioma amplified sequence (GAS41), a highly conserved putative transcription factor. Oncogene, 20, 4853-4863.

6. Chong,S., Riggs,A.D. and Bonifer,C. (2002) The chicken lysozyme chromatin domain contains a second, widely expressed gene. Nucleic Acids Res., 30, 463-467.

7. Mitchell,P.J. and Tjian,R. (1989) Transcriptional regulation in mammalian cells by sequence-specific DNA binding proteins. Science, $\mathbf{2 4 5}, \mathbf{3 7 1 - 3 7 8}$

8. Debernardi,S., Bassini,A., Jones,L.K., Chaplin,T., Linder,B., de Bruijn,D.R., Meese,E. and Young,B.D. (2002) The MLL fusion partner AF10 binds GAS41, a protein that interacts with the human SWI/SNF complex. Blood, 99, 275-281.

9. Prochasson,P., Neely,K.E., Hassan,A.H., Li,B. and Workman,J.L. (2003) Targeting activity is required for SWI/SNF function in vivo and is accomplished through two partially redundant activator-interaction domains. Mol. Cell, 12, 983-990.

10. Harborth,J., Weber,K. and Osborn,M. (2000) GAS41, a highly conserved protein in eukaryotic nuclei, binds to NuMA. J. Biol. Chem., 275 , 31979-31985.

11. Zimmermann,K., Ahrens,K., Matthes,S., Buerstedde,J.M., Stratling,W.H. and Phi-van,L. (2002) Targeted disruption of the GAS41 gene encoding a putative transcription factor indicates that GAS41 is essential for cell viability. J. Biol. Chem., 277, 18626-18631.

12. Gonda,T.J. (1998) The c-Myb oncoprotein. Int. J. Biochem. Cell Biol., 30, 547-551.

13. Mucenski,M.L., McLain,K., Kier,A.B., Swerdlow,S.H., Schreiner,C.M., Miller,T.A., Pietryga,D.W., Scott,W.J.,Jr and Potter,S.S. (1991) A functional c-myb gene is required for normal murine fetal hepatic hematopoiesis. Cell, 65, 677-689.

14. Biedenkapp,H., Borgmeyer,U., Sippel,A.E. and Klempnauer,K.H. (1988) Viral myb oncogene encodes a sequence-specific DNA-binding activity. Nature, 335, 835-837.

15. Klempnauer,K.H., Arnold,H. and Biedenkapp,H. (1989) Activation of transcription by v-myb: evidence for two different mechanisms. Genes Dev., 3, 1582-1589.

16. Ness,S.A., Marknell,A. and Graf,T. (1989) The v-myb oncogene product binds to and activates the promyelocyte-specific mim- 1 gene. Cell, 59, 1115-1125.

17. Weston,K. and Bishop,J.M. (1989) Transcriptional activation by the v-myb oncogene and its cellular progenitor, c-myb. Cell, 58, 85-93.

18. Ibanez,C.E. and Lipsick,J.S. (1990) Transactivation of gene expression by v-myb. Mol. Cell. Biol., 10, 2285-2293.

19. Introna,M., Golay,J., Frampton,J., Nakano,T., Ness,S.A. and Graf,T. (1990) Mutations in v-myb alter the differentiation of myelomonocytic cells transformed by the oncogene. Cell, 63, 1289-1297.
20. Frampton,J., Ramqvist,T. and Graf,T. (1996) v-Myb of E26 leukemia virus up-regulates bcl-2 and suppresses apoptosis in myeloid cells. Genes Dev., 10, 2720-2731.

21. Taylor,D., Badiani,P. and Weston,K. (1996) A dominant interfering Myb mutant causes apoptosis in T cells. Genes Dev., 10, 2732-2744.

22. Burk,O., Worpenberg,S., Haenig,B. and Klempnauer,K.H. (1997) tom-1, a novel v-Myb target gene expressed in AMV-and E26-transformed myelomonocytic cells. EMBO J., 16, 1371-1380.

23. Kowenz-Leutz,E., Herr,P., Niss,K. and Leutz,A. (1997) The homeobox gene GBX2, a target of the myb oncogene, mediates autocrine growth and monocyte differentiation. Cell, 91, 185-195.

24. Burk,O., Mink,S., Ringwald,M. and Klempnauer,K.H. (1993) Synergistic activation of the chicken mim-1 gene by v-myb and C/EBP transcription factors. EMBO J., 12, 2027-2038.

25. Klempnauer,K.H., Ramsay,G., Bishop,J.M., Moscovici,M.G., Moscovici,C., McGrath,J.P. and Levinson,A.D. (1983) The product of the retroviral transforming gene $\mathrm{v}$-myb is a truncated version of the protein encoded by the cellular oncogene c-myb. Cell, 33, 345-355.

26. Burk,O. and Klempnauer,K.H. (1991) Estrogen-dependent alterations in differentiation state of myeloid cells caused by a v-myb/estrogen receptor fusion protein. EMBO J., 10, 3713-3719.

27. Burk,O. and Klempnauer,K.H. (1999) Myb and Ets transcription factors cooperate at the myb-inducible promoter of the tom-1 gene. Biochim. Biophys. Acta, 1446, 243-252.

28. Oehler,T., Arnold,H., Biedenkapp,H. and Klempnauer,K.H. (1990) Characterization of the v-myb DNA binding domain. Nucleic Acids Res., 18, 1703-1710.

29. Giacca,M., Pelizon,C. and Falaschi,A. (1997) Mapping replication origins by quantifying relative abundance of nascent DNA strands using competitive polymerase chain reaction. Methods, 13, 301-312.

30. Phi-van,L. and Stratling,W.H. (1988) The matrix attachment regions of the chicken lysozyme gene co-map with the boundaries of the chromatin domain. EMBO J., 7, 655-664.

31. Bell,A.C. and Felsenfeld,G. (1999) Stopped at the border: boundaries and insulators. Curr. Opin. Genet. Dev., 9, 191-198.

32. Bonifer,C. (2000) Developmental regulation of eukaryotic gene loci: which cis-regulatory information is required? Trends Genet., 16, 310-315.

33. Phi-van,L., Sellke,C., von Bodenhausen,A. and Stratling,W.H. (1998) An initiation zone of chromosomal DNA replication at the chicken lysozyme gene locus. J. Biol. Chem., 273, 18300-18307.

34. Phi-van,L. and Stratling,W.H. (1999) An origin of bidirectional DNA replication is located within a CpG island at the 3" end of the chicken lysozyme gene. Nucleic Acids Res., 27, 3009-3017.

35. Worpenberg,S., Burk,O. and Klempnauer,K.H. (1997) The chicken adenosine receptor $2 \mathrm{~B}$ gene is regulated by v-myb. Oncogene, $\mathbf{1 5}$, 213-221.

36. Schlichter,U., Burk,O., Worpenberg,S. and Klempnauer,K.H. (2001) The chicken Pdcd 4 gene is regulated by v-Myb. Oncogene, 20, 231-239.

37. Ness,S.A., Kowenz-Leutz,E., Casini,T., Graf,T. and Leutz,A. (1993) Myb and NF-M: combinatorial activators of myeloid genes in heterologous cell types. Genes Dev., 7, 749-759.

38. Beall,E.L., Manak,J.R., Zhou,S., Bell,M., Lipsick,J.S. and Botchan,M.R. (2002) Role for a Drosophila Myb-containing protein complex in site-specific DNA replication. Nature, 420, 833-837.

39. Danis,E., Brodolin,K., Menut,S., Maiorano,D., Girard-Reydet,C. and Mechali,M. (2004) Specification of a DNA replication origin by a transcription complex. Nature Cell Biol., 6, 721-730.

40. Lefevre,P., Melnik,S., Wilson,N., Riggs,A.D. and Bonifer,C. (2003) Developmentally regulated recruitment of transcription factors and chromatin modification activities to chicken lysozyme cis-regulatory elements in vivo. Mol. Cell. Biol., 23, 4386-4400. 